\title{
Outcomes from cardiac surgery in Jehovah's witness patients: experience over twenty-one years
}

\author{
Sotirios Marinakis ${ }^{1}$, Philippe Van der Linden², Redente Tortora ${ }^{1}$, Jacques Massaut ${ }^{3}$, Charalampos Pierrakos ${ }^{3}$ \\ and Pierre Wauthy ${ }^{1 *}$
}

\begin{abstract}
Background: Cardiac surgery in Jehovah's Witnesses may be challenging during the operation and postoperative period given their refusal of blood products. The aim of this study was to document our center's experience with Jehovah's Witnesses undergoing major cardiac surgery and to compare surgical outcomes with a matched control group.

Methods: We retrospectively reviewed the demographic, perioperative, and in-hospital postoperative data for 31 Jehovah's Witness patients undergoing surgery from 1991 to 2012 and compared findings with a control group of 62 patients of the same sex and age, who underwent the same type of operations in the same period. Early mortality, major in-hospital morbidity, laboratory findings, and hospital stays were compared between groups.

Results: Demographic data were similar between groups, except that more patients in the Jehovah's Witness group had extracardiac arteriopathy compared with controls $(p=0.04)$. There was no difference in predicted mortality, calculated by the Euroscore II, between groups ( $2.8 \pm 3.3$ in study group versus $2.4 \pm 2.2$ in control group, $p=0.469)$. For postoperative outcomes, there were no differences between Jehovah's Witnesses versus controls in hospital mortality ( $3 \%$ versus $2 \%, p=0.548$ ), total drain loss $(847 \pm 583 \mathrm{~mL}$ versus $812 \pm 365 \mathrm{~mL}$, $p=0.721)$, mechanical ventilation time (1.26 \pm 2.24 versus $0.89 \pm 0.55$ days, $p=0.218)$, intensive care unit stay $(4.3 \pm 3.9$ versus $3 \pm 1.4$ days, $p=0.080)$, and hospital stay ( $12.9 \pm 7.6$ versus $10.9 \pm 6.6$ days, $p=0.223$ ).
\end{abstract}

Conclusions: Outcomes after cardiac surgery are similar between Jehovah's Witnesses and general population, in centers applying rigorous blood patient management protocols.

Keywords: Bleeding, Blood transfusion, Cardiopulmonary bypass, Cell saver, Reoperation

\section{Background}

Jehovah's Witnesses refuse the transfusion of blood products, based on Biblical passages citing to "abstain from food polluted by idols, from sexual immorality, from the meat of strangled animals and from blood" (Acts 15:19-20). Before major surgery, these patients are confronted with the stress of both the operation and the potential need for transfusion. The role of the health care provider is to assure the physical and psychological welfare of patients while respecting their philosophical

\footnotetext{
*Correspondence: pierre.wauthy@chu-brugmann.be

${ }^{1}$ Department of Cardiac Surgery, Brugmann University Hospital, Laeken, Belgium

Full list of author information is available at the end of the article
}

and religious beliefs. However, despite the important evolution of blood preservation techniques, there is still a great risk for transfusion in cardiac surgery. Transfusion rates during hospitalization for a cardiac surgery procedure vary from 25 to $95 \%$ [1-3]. In this context, cardiac surgery in Jehovah's Witnesses represents a real challenge, necessitating a close collaboration between the surgical, anesthesiological, and medical teams. However, due to the Jehovah's Witnesses' "natural experiment of blood abstention", the overall need for transfusion during cardiac surgery should be reevaluated [4]. Recent studies did not find any difference in terms of mortality between Jehovah's Witnesses and a control group after 
cardiac surgery [4-7]. Moreover, the deleterious effects of blood transfusions in terms of postoperative morbidity and long term mortality after cardiac surgery, along with the cost and shortage of available blood products, suggest tighter transfusion protocols [1, 2, 8-11]. In this context, the investigation of surgical outcomes in Jehovah's Witnesses helps to evaluate the limits of transfusion safety and cut off points for transfusion, while improving the hospital care of this challenging group of patients [12]. The aim of this study was to document our center's experience with complex cardiac surgery, including reoperations and urgent operations, in a non-selected Jehovah's Witness group and to compare surgical outcomes with a matched control group.

\section{Methods}

The current retrospective study was carried out by the Cardiac Surgery Department of Brugmann University Hospital in Brussels. All adult Jehovah's Witness patients operated in our hospital from 1991 to $2012(n=31)$ were identified through our computerized database. Baseline demographics, perioperative data, postoperative outcomes, and laboratory data (Tables 1, 2, 3 and 4) were recorded after consultation of each patient's chart and admission medical history. For each of the 31 Jehovah's Witnesses, the previous and the next patient of the same sex who underwent the same surgical procedure were included in the control group if their age difference from the Jehovah's Witness patient was $\leq 5$ years. All patients were operated on by the same surgical team consisting of four senior surgeons (Table 1).

The same anesthesia protocol, surgical techniques, extracorporeal circulation, myocardial protection, and blood salvage techniques were used for both groups. A coated circuit with open venous reservoir and a centrifugal pump was used for extracorporeal circulation. Priming, consisted of only $1 \mathrm{~L}$ of colloid solution (modified fluid gelatin) and $150 \mathrm{mg}$ of $20 \%$ mannitol. Whenever patient's

Table 1 Patients' demographics

\begin{tabular}{|c|c|c|c|}
\hline & Jehovah's Witnesses $(n=31)$ & Control Group $(n=62)$ & $p$ Value \\
\hline Age in years & $62 \pm 15$ & $62 \pm 14$ & 0.873 \\
\hline $\mathrm{BMI}\left(\mathrm{kg} / \mathrm{m}^{2}\right)$ & $27.4 \pm 4.3$ & $26.2 \pm 4.0$ & 0.182 \\
\hline Women & $10(32 \%)$ & $20(32 \%)$ & 1.000 \\
\hline Number of operations per surgeon $(1,2,3,4)$ & $13,10,4,4$ & $15,27,12,8$ & 0.344 \\
\hline Euroscore II & $2.80 \pm 3.34$ & $2.38 \pm 2.20$ & 0.469 \\
\hline Preoperative Cockcroft's CC in mL/min & $84 \pm 29$ & $82 \pm 27$ & 0.776 \\
\hline Renal insufficiency (Cockcroft's CC $<85 \mathrm{~mL} / \mathrm{min}$ ) & $16(52 \%)$ & $34(55 \%)$ & 0.769 \\
\hline Diabetes & $8(26 \%)$ & $15(24 \%)$ & 0.865 \\
\hline Recent smoker & $3(10 \%)$ & $17(27 \%)$ & 0.062 \\
\hline Hypertension & $18(58 \%)$ & $30(48 \%)$ & 0.379 \\
\hline Hypercholesterolemia & $19(61 \%)$ & $36(58 \%)$ & 0.765 \\
\hline Positive family history & $10(32 \%)$ & $18(29 \%)$ & 0.749 \\
\hline Cerebrovascular accident & $4(13 \%)$ & $5(9 \%)$ & 0.457 \\
\hline Peripheral vascular disease & $8(26 \%)$ & $6(10 \%)$ & 0.040 \\
\hline Previous myocardial infarction & $6(19 \%)$ & $11(18 \%)$ & 0.850 \\
\hline Recent myocardial infarction (<90 days) & $3(10 \%)$ & $6(10 \%)$ & 1.000 \\
\hline COPD & $6(19 \%)$ & $6(10 \%)$ & 0.189 \\
\hline NYHA & & & 0.452 \\
\hline I & $6(19 \%)$ & $7(11 \%)$ & - \\
\hline$\|$ & $12(39 \%)$ & $21(34 \%)$ & - \\
\hline III & $10(32 \%)$ & $30(48 \%)$ & - \\
\hline IV & $3(10 \%)$ & $4(6 \%)$ & - \\
\hline Preoperative LVEF (\%) & $62 \pm 11$ & $59 \pm 14$ & 0.340 \\
\hline Preoperative AF & $5(16 \%)$ & $9(15 \%)$ & 0.838 \\
\hline Reoperation & $3(10 \%)$ & $8(13 \%)$ & 0.650 \\
\hline Urgent status & 7 (23\%) & 6 (10\%) & 0.091 \\
\hline
\end{tabular}

$B M I$ body mass index, CC creatinine clearance, Recent smoker current smoker or ex-smoker for less than 5 years, COPD chronic obstructive pulmonary disease, NYHA New York heart association score, AF atrial fibrillation, LVEF left ventricular ejection fraction 
Table 2 Type of surgery

\begin{tabular}{lll}
\hline Type of operation & $\begin{array}{l}\text { Jehovah's Witnesses } \\
(n=31)\end{array}$ & $\begin{array}{l}\text { Control group } \\
(n=62)\end{array}$ \\
\hline CABG & $15(48 \%)$ & $30(48 \%)$ \\
CABG beating heart & $2(6 \%)$ & $4(6 \%)$ \\
AVR & $5(16 \%)$ & $10(16 \%)$ \\
MVR & $2(6 \%)$ & $4(6 \%)$ \\
Double VR & $2(6 \%)$ & $4(6 \%)$ \\
Combined VR + CABG & $3(10 \%)$ & $6(10 \%)$ \\
Bentall & $1(3 \%)$ & $2(3 \%)$ \\
AAR & $1(3 \%)$ & $2(3 \%)$
\end{tabular}

CABG coronary artery bypass graft, $A V R$ aortic valve replacement, MVR mitral valve replacement, $V R$ valve replacement, $A A R$ ascending aortic replacement

hemodynamic state permitted it, retropriming technique was used to further reduce hemodilution. All the patients were maintained with an hematocrit up to $24 \%$ and hemofiltration was systematically performed. All the procedures were achieved under mild hypothermia (between 32 and $33{ }^{\circ} \mathrm{C}$ ). The cardiopulmonary flow rate was maintained between 2,8 and $3 \mathrm{~L} / \mathrm{min} / \mathrm{m} 2$ and the $\mathrm{FiO} 2$ (inspired oxygen fraction) was adapted to maintain a $\mathrm{SvO} 2$ (venous saturation in oxygen) above the $75 \%$ threshold.

From 1991 to 2007, aprotinin was routinely administered in the priming solution as an antifibrinolytic agent and replaced thereafter by tranexamic acid [13]. For all operations where the ascending aorta was opened, retrograde cardioplegia was administered. For operations with an intact aortic root and competent aortic valve, anterograde cardioplegia was administered from the ascending aorta. From 1991 to 2010, a modified Saint Thomas crystalloid cold cardioplegia was used, subsequently replaced by a cold blood cardioplegia $\left(8{ }^{\circ} \mathrm{C}\right)$ diluted with $23 \%$ crystalloid solutions. Significant blood loss was systematically processed with a Cell Saver. For the Jehovah's Witness group, a continuous connection between the Cell Saver's washed blood bag and the patient's peripheral intra-venous infusion line was used in accordance with their beliefs for continuous blood flow.
After 2003, all Jehovah's Witness patients undergoing elective surgery were evaluated preoperatively to optimize their red blood cell volume. When hemoglobin was less than $13 \mathrm{~g} / \mathrm{dL}$, a total of three subcutaneous injections of 40000 units of erythropoietin and intravenous iron were administered 3, 2, and 1 week before the operation. Control group patients did not receive any erythropoietin treatment, as it is not reimbursed by the Belgium national health care system for cardiac surgery. Oral anticoagulation therapy was routinely discontinued 3 days before surgery and replaced with fractionated heparin. Platelet anti-aggregation therapy was routinely discontinued 7 days before elective surgery cases $[9,10]$.

Univariate analysis of demographics as well as preoperative, operative, and postoperative in-hospital variables was performed between the two groups. Comparisons between continuous variables were performed using the Student $t$-test after the Levene's test for equality of variances. Dichotomous variables were compared using the $X^{2}$ or the Fisher's exact test for cell counts $<5$. A $p$ value $\leq 0.05$ was considered significant and all tests were 2-sided. All parametric data are presented as the mean value \pm standard deviation. Statistical analysis was performed with SPSS 20.0.

\section{Results}

In our study, the Jehovah's Witness group underwent a variety of cardiac surgery procedures, included reoperations and urgent procedures. The control group was selected based on the type of surgical procedure as described in the methods (Table 2). Demographic characteristics of Jehovah's Witnesses versus the controls are presented in Table 1. Univariate analysis showed that the groups had similar demographics and preoperative characteristics. The Euroscore II was calculated for both groups and there was no difference in predicted mortality $(p=0.469)$. The left ventricular ejection fraction was also similar between groups $(p=0.340)$. The only significant difference between groups was that Jehovah's Witnesses had more peripheral vascular disease than controls $(p=0.040$, Table 1$)$.

Table 3 Laboratory findings

\begin{tabular}{|c|c|c|c|c|c|c|c|c|c|}
\hline & $\mathrm{Hb}(\mathrm{g} / \mathrm{dL})$ & & & Plat $(\times 1000 /$ & & & $\mathrm{Cr}(\mathrm{mg} / \mathrm{dL})$ & & \\
\hline & JhW & $C G$ & $p$ & $\mathrm{JhW}$ & $C G$ & $P$ & JhW & $C G$ & $p$ \\
\hline$D_{-1}$ & $14.2 \pm 1.6$ & $13.7 \pm 1.7$ & 0.174 & $226.4 \pm 55.2$ & $233.7 \pm 75$ & 0.640 & $1.13 \pm 0.29$ & $1.08 \pm 0.20$ & 0.272 \\
\hline$D_{0}$ & $10.6 \pm 1.8$ & $10.4 \pm 1.3$ & 0.478 & $156.3 \pm 38.9$ & $156.0 \pm 47.4$ & 0.974 & $1.13 \pm 0.29$ & $1.05 \pm 0.22$ & 0.112 \\
\hline $\mathrm{D}_{1}$ & $11.0 \pm 2.0$ & $10.9 \pm 1.5$ & 0.849 & $179.7 \pm 50.8$ & $179.3 \pm 55.4$ & 0.977 & $1.28 \pm 0.48$ & $1.15 \pm 0.30$ & 0.123 \\
\hline $\mathrm{D}_{2}$ & $10.5 \pm 2.2$ & $10.5 \pm 1.2$ & 0.995 & $177.9 \pm 66.3$ & $167.6 \pm 58.3$ & 0.468 & $1.18 \pm 0.55$ & $1.03 \pm 0.41$ & 0.160 \\
\hline $\mathrm{D}_{5}$ & $10.7 \pm 2.5$ & $11.0 \pm 1.7$ & 0.513 & $220.1 \pm 85.5$ & $227.5 \pm 87.7$ & 0.732 & $1.12 \pm 0.53$ & $1.03 \pm 0.50$ & 0.445 \\
\hline $\mathrm{D}_{7}$ & $10.7 \pm 2.5$ & $11.4 \pm 1.8$ & 0.218 & $298.9 \pm 93.1$ & $329 \pm 106.7$ & 0.301 & $1.17 \pm 0.67$ & $1.13 \pm 0.69$ & 0.862 \\
\hline
\end{tabular}

JHW Jehovah's witnesses, CG control group, $H b$ hemoglobin, Plat platelets, $C r$ creatinine, $D_{-1}$ preoperative, $D_{0}-D_{7}$ Day 0-Day 7 
Table 4 Postoperative outcomes

\begin{tabular}{|c|c|c|c|}
\hline & Jehovah's Witnesses & Control group & $P$ value \\
\hline Time of ECC in min & $104 \pm 35$ & $98 \pm 36$ & 0.432 \\
\hline Cross Clamp Time in min & $61 \pm 27$ & $59 \pm 29$ & 0.721 \\
\hline Perioperative blood loss in $\mathrm{mL}$ & $209 \pm 235$ & $308 \pm 367$ & 0.178 \\
\hline Drain $24 \mathrm{~h}$ in $\mathrm{mL}$ & $644 \pm 458$ & $582 \pm 215$ & 0.481 \\
\hline Drain total in $\mathrm{mL}$ & $847 \pm 583$ & $812 \pm 365$ & 0.721 \\
\hline Hours post drain ablation & $46.3 \pm 9.8$ & $45.7 \pm 12.1$ & 0.811 \\
\hline LVEF postop (\%) & $57 \pm 8$ & $58 \pm 10$ & 0.912 \\
\hline Mechanical ventilation in days & $1.26 \pm 2.24$ & $0.89 \pm 0.55$ & 0.218 \\
\hline ICU stay in days & $4.3 \pm 3.9$ & $3.0 ? \pm 1.4$ & 0.080 \\
\hline Postoperative length of stay in days & $12.9 \pm 7.6$ & $10.9 \pm 6.6$ & 0.223 \\
\hline IABP & $1(3 \%)$ & 0 & 0.333 \\
\hline Acute Ml & 0 & $1(2 \%)$ & 1.000 \\
\hline Stroke & 0 & 0 & - \\
\hline New onset AF & $11(35 \%)$ & $11(18 \%)$ & 0.058 \\
\hline New AF on discharge & 0 & $3(5 \%)$ & 0.548 \\
\hline Max Cr postop (mg/dL) & $1.43 \pm 0.60$ & $1.32 \pm 0.60$ & 0.378 \\
\hline Min Cockcroft's CC postop (mL/min) & $63.8 \pm 32.3$ & $64.8 \pm 24.8$ & 0.865 \\
\hline Hemodialysis & $1(3 \%)$ & 0 & 0.333 \\
\hline Hemorrhage related re-exploration & $2(6 \%)$ & $1(2 \%)$ & 0.257 \\
\hline Mediastinitis & $1(3 \%)$ & $1(2 \%)$ & 1.000 \\
\hline Serious infectious complications & $5(16 \%)$ & $3(5 \%)$ & 0.112 \\
\hline Transfused patients & 0 & $17(27.4 \%)$ & 0.001 \\
\hline Units of RBC & 0 & 39 & - \\
\hline Units of RBC pp & $0 \pm 0$ & $0.63 \pm 1.5$ & 0.002 \\
\hline Operative mortality & $1(3 \%)$ & $1(2 \%)$ & 0.548 \\
\hline
\end{tabular}

ECC extracorporeal circulation, ICU intensive care unit, $L V E F$ left ventricular ejection fraction, postop = postoperative, $R B C$ red blood cells, IABP intra-aortic balloon pump, MI myocardial infarction, Max maximum, Cr creatinine, Min minimum, CC creatinine clearance, $p p$ per patient, Serious infectious complications Pneumonia, Mediastinitis, Bacteremia

Hemoglobin, platelet, and serum creatinine values were compared between groups one day preoperatively and on days $0,1,2,5$, and 7 postoperatively and there was no significant difference at any time between groups (Table 3). Perioperative variables and postoperative outcomes are grouped in Table 4. No difference was observed in the time of extracorporeal circulation, aortic clamping, or perioperative blood loss. Drains were withdrawn within two days after the operation and their output was similar between groups $(p=0.721)$. One patient from each group underwent a reoperation for mediastinitis $(p=1.000)$. Two reoperations for hemorrhage or tamponade were performed in Jehovah's Witnesses versus one in the control group $(p=0.257)$. No significant difference was observed in postoperative renal function, as defined by the maximum postoperative serum creatinine $(p=0.378)$ and the minimum postoperative creatinine clearance $(p=0.865)$. One Jehovah's Witness developed severe renal failure at day1 necessitating hemodialysis. This patient developed multi-organ failure in sepsis post-mediastinitis and died in the intensive care unit on day 37 after a triple coronary artery bypass. This patient suffered from insulin depending diabetes with a preoperative logistic euroscore II of 15.09. Preoperative creatinine level and estimated creatinine clearance were respectively $2,04 \mathrm{mg} / \mathrm{dL}$ and $30,0 \mathrm{~mL} / \mathrm{min}$. He was operated in an urgent status because of a non ST elevation myocardial infarction. Minimal hemoglobin level during extracorporeal circulation was $9,4 \mathrm{gr} / \mathrm{dL}$ and minimal hemoglobin level the day of the procedure was $8,4 \mathrm{gr} / \mathrm{dL}$. The hemoglobin level rose progressively up to $12,4 \mathrm{gr} / \mathrm{dL}$ at postoperative day seven.

There was no significant difference in surgical outcomes. Hospital mortality was $3 \%$ for Jehovah's Witnesses versus $2 \%$ for control group, $p=0.548$. The postoperative left ventricular ejection fraction was similar between groups $(p=0.912)$. No stroke was observed in our series. One control patient had acute myocardial infarction but 
did not require a prolonged hospital stay. One Jehovah's Witness, who underwent surgery for an off pump coronary artery bypass, required $12 \mathrm{~h}$ of intra-aortic balloon pump support immediately after surgery. No significant differences were found in the lengths of the mechanical ventilation support $(p=0.218)$, the intensive care unit stay $(p=0.080)$, or the postoperative stay $(p=0.223$, Table 4$)$. Only 17 of the $62(27.4 \%)$ control group patients were transfused with a total of 39 units of red blood cells concentrates $(0.63 \pm 1.5$ units per patient, $2.3 \pm 2.2$ units per transfused patient). No Jehovah's Witness patient was transfused (Table 4, Figs. 1 and 2).

\section{Discussion}

In the current study we presented the outcomes after cardiac surgery for a non-selected group of Jehovah's Witnesses $(n=31)$ operated in our cardiac surgery department from 1991 to 2012. Outcomes and demographic variables were compared with a matched control group $(n=62)$ as described above. No difference was demonstrated in terms of hospital mortality, in-hospital morbidity, or the intensive care or hospital length of stay. Hemoglobin levels remained similar between groups, both pre- and postoperatively.
Previous, non-comparative studies provided evidence that cardiac surgery can be safely performed in Jehovah's Witnesses, with acceptable outcomes in terms of mortality and morbidity [14-18]. Moreover, a literature search identified four retrospective comparative studies evaluating cardiac surgery in Jehovah's Witnesses in comparison to a control group of patients. Three studies compared outcomes after cardiac surgery between Jehovah's Witnesses and a control group of matched transfused patients [4, 6, 7] and another one between Jehovah's Witnesses and a matched group regardless of blood transfusion [5]. A comparison of the major demographic data and surgical outcomes between our study and previous comparative studies is shown in Table 5.

Our Jehovah's Witness group differed significantly from other studies regarding the type of cardiac surgery procedures. Patients underwent a variety of high risk surgical procedures, including urgent operations, reoperations, double valve surgery, combined valve and coronary surgery and ascending aorta procedures (Tables 2, 5). More precisely, in our group only $54 \%$ of all procedures were isolated coronary bypass surgery; whereas, El Azab et al. [5] reported more than $90 \%$ coronary by-pass surgeries for the Jehovah's Witness group. In the other three studies, which compared Jehovah's Witnesses to a matched



Fig. 1 Comparison of mean hemoglobin over time for Control Group transfused, Control Group not transfused, and Jehovah's Witness patients. (CG = Control Group, JhW = Jehovah's Witnesses, $\mathrm{Hb}=$ Hemoglobin, Preop = Preoperative, $\mathrm{Cl}=$ Confidence Intervals) 


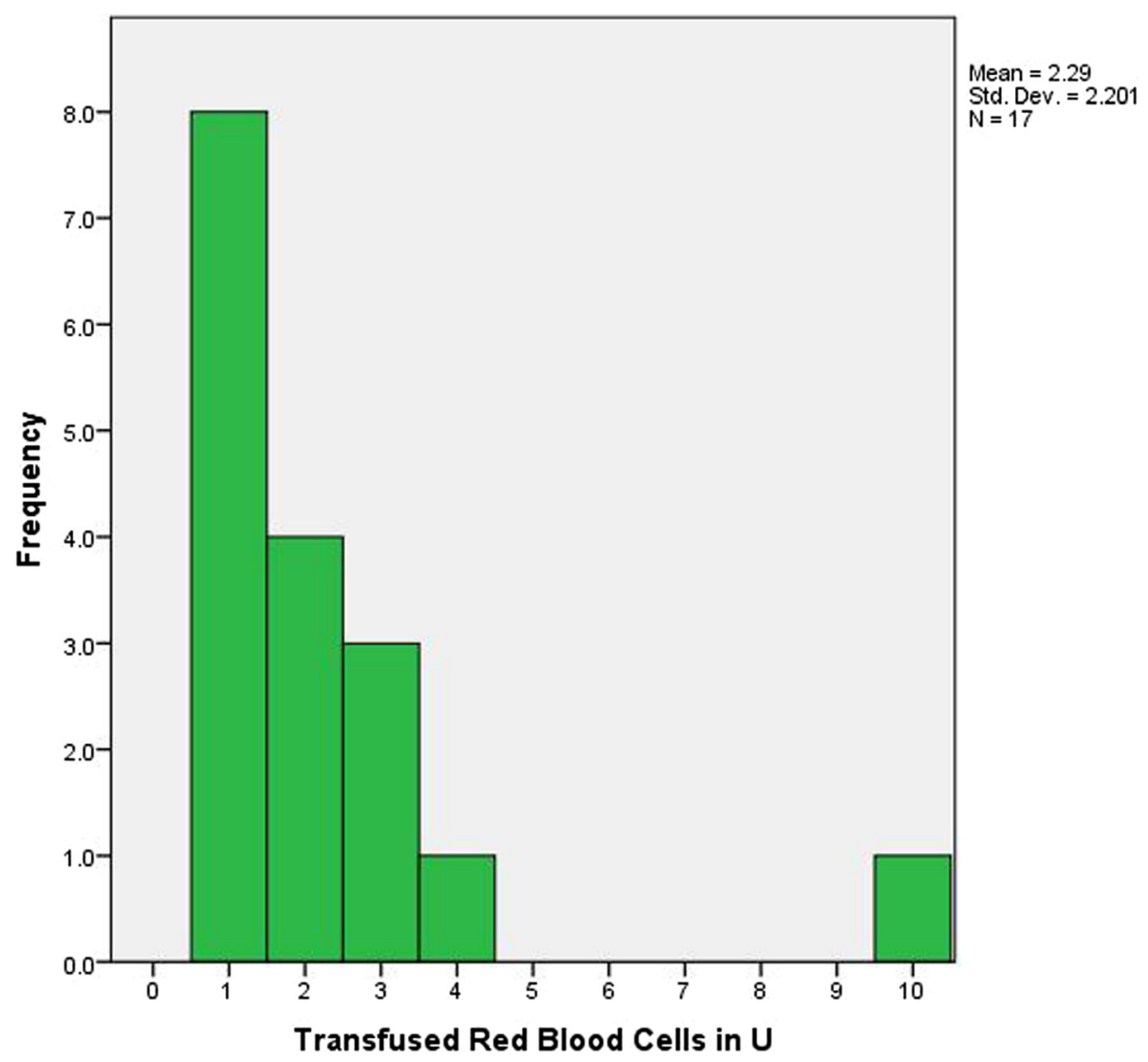

Fig. 2 Histogram of transfused Red Blood Cells in Units

transfused group, coronary bypass surgery accounted for $51 \%, 65 \%$, and $78 \%$ of all cases [4, 6, 7]. Moreover, in our study, $10 \%$ of all procedures were reoperations, which were not reported in the other studies (Table 5).

Despite a trend towards more complex operations, our results are in agreement with previous studies [4-7]. In terms of surgical outcomes, no difference was observed in early operative mortality. There was a trend towards a prolonged intensive care unit length of stay for Jehovah's Witness group, who stayed 1.3 days more than control group $(p=0.08)$. This difference was in part due to two Jehovah's Witnesses, who required prolonged intensive care unit hospitalization (14 and 21 days) due to hemoglobin values less than $5.5 \mathrm{~g} / \mathrm{dL}$ during the postoperative period. Blood restriction was respected according to the patient's convictions. If these patients were excluded from the analysis as outliners, the new intensive care unit length of stay would be $3.4 \pm 1.6$ days $(p=0.215)$, which is closer to control group. Nevertheless, we believe that both values should be discussed, as the prolonged intensive care unit stay was related to their refusal of transfusion. Both were released from the hospital uneventfully on postoperative day 28. Both groups of patients had equivalent postoperative lengths of stay. No difference was found with regard to perioperative and postoperative blood loss, suggesting no preferential surgical hemostasis between groups. Two patients had a revision for bleeding in the Jehovah's Witness group. The first had a preoperative hemoglobin level of $14.4 \mathrm{gr} / \mathrm{dL}$. He was reoperated at J0 after a major operation. No apparent source of hemorrhage was found. This patient presented after the reoperation an hemoglobin level of $9.6 \mathrm{gr} / \mathrm{dL}$. The patient was discharged uneventfully from the hospital at day 11 . The second patient belongs to the group of the two patients exhibiting a hemoglobin level below 5.5gr/dL. He underwent a CABG (coronary arterial bypass graft) procedure and was been reoperated during the following night (12 h after operation). The source of bleeding was in the field of the dissection of the mammary artery. He had a preoperative hemoglobin of $17.3 \mathrm{gr} / \mathrm{dL}$. The hemoglobin level after the reoperation was $8 \mathrm{gr} / \mathrm{dL}$ and at reached its minimal levels of $5.2 \mathrm{gr} / \mathrm{dL}$ at postoperative day 7 . The patient was discharged at day 28. In both groups, drains were withdrawn within the first $48 \mathrm{~h}$. No difference was revealed in terms of postoperative morbidity. The patient who died in the Jehovah's Witness group was a high risk patient. Preoperative chronic renal insufficiency was the cause of the acute renal failure observed at postoperative 
Table 5 Comparison of current study with previous retrospective comparative studies

\begin{tabular}{|c|c|c|c|c|c|}
\hline & $\begin{array}{l}\text { Marinakis ( } n=31 \mathrm{JhWs} \\
\text { vs. } 62 \text { CG patients) }\end{array}$ & $\begin{array}{l}\text { El Azab [5] ( } n=123 \mathrm{JhWs} \\
\text { vs. } 4219 \text { CG patients) }\end{array}$ & $\begin{array}{l}\text { Stamou [7] ( } n=49 \mathrm{JhWs} \\
\text { vs. } 196 \text { transfused patients) }\end{array}$ & $\begin{array}{l}\text { Bhaskar [6] ( } n=49 \mathrm{JhWs} \\
\text { vs. } 196 \text { transfused patients) }\end{array}$ & $\begin{array}{l}\text { Pattakos [4] ( } n=322 \mathrm{JhWs} \\
\text { vs. } 322 \text { transfused patients) }\end{array}$ \\
\hline Isolated CABG & $15(48 \%)$ & 112 (91 \%) & $38(78 \%)$ & $25(51 \%)$ & $209(65 \%)$ \\
\hline Combined surgery & $7(22.6 \%)$ & $10(8.1)$ & $2(4 \%)$ & $11(22.4 \%)$ & $16(5 \%)$ \\
\hline Reoperation & $3(9.7 \%)$ & - & 0 & - & - \\
\hline ICU LOS & $4.3 \pm 3.9(p=0.08)$ & $2.3 \pm 3.2(p=0.16)$ & $1.5 \pm 1.3(p=0.22)$ & $1 \pm 0.4(p=0.81)$ & $1(50 \%$ perc $)(p=0.001)$ \\
\hline In-hospital mortality & $1(3 \%)(p=0.55)$ & $3(2.7 \%)(p=0.59)$ & $3(6 \%)(p=0.63)$ & $1(2 \%)(p=0.52)$ & $10(3 \%)(p=0.40)$ \\
\hline Postoperative infarct & $0(p=1.00)$ & $2(1.8 \%)(p=0.02)$ & $0(p=0.62)$ & $0(p=0.62)$ & $1(0.3)(p=0.01)$ \\
\hline
\end{tabular}


day one. Effectively, the mild hemodilution observed during cardiopulmonary bypass doesn't explain this acute renal failure. The progressive rise in hemoglobin the week following the operation and the occurrence of a general sepsis after a mediastinitis at postoperative day 7 probably exclude that this patient died because of transfusion refusal.

No statistically significant difference was found between groups in the preoperative or postoperative period for hemoglobin and creatinine concentrations or platelet counts (Table 3). Among the control group, the mean preoperative hemoglobin value was significantly less in transfused patients $(12.5 \pm 2.1 \mathrm{~g} / \mathrm{dL}$ versus $14.2 \pm 1.3 \mathrm{~g} / \mathrm{dL}$ for the non-transfused control group, $p=0.001$, Fig. 1). This finding is indicative of the importance of "normal" preoperative hemoglobin levels to reduce the need for red blood cell transfusions [19]. Erythropoietin was administered to 4 Jehovah's Witnesses preoperatively for low hemoglobin and to 3 more during hospitalization for the same reason. Our center is especially interested in patient blood management strategies; therefore, we adopted a restricted transfusion policy for all the population we are taking in charge. In this study, only 17 of 62 (27.4 \%) patients in the control group were transfused with a total of 39 units of red blood cells. Eight of them received only 1 unit of red blood cells and four of them 2 units (Fig. 2). We can reasonably assume that some patients who received only one unit, were transfused to correct a possible hemodilution status frequently present at least until the 3rd postoperative day. These patients could have avoided blood transfusion if a more clinically-oriented approach had been used. Thus, although our transfusion rate is very competitive with regards to the literature, further improvement in blood saving is still possible.

Current literature reports transfusion rates from $25 \%$ to $95 \%[1,2,11]$, with an average rate around $50 \%$ [20]. Blood transfusion in cardiac surgery is associated with several adverse effects. A recent meta-analysis concerning the risk of red blood cell transfusions in cardiac surgery reported that transfused patients are at greater risk of developing postoperative infectious complications and acute myocardial infarction, have prolonged length of stay postoperatively in the intensive care unit and hospital, and have increased long term mortality [1]. Moreover, red blood cell transfusion is associated with a significantly increased hospital cost [1]. On the other hand, there are situations where a blood transfusion is lifesaving. It has been reported that hemoglobin levels $<7 \mathrm{~g} / \mathrm{dL}$ in surgical patients who refused blood transfusion, regardless of type of surgery, is associated with higher morbidity and mortality [12]. The same study reported a mortality of more than $40 \%$ for patients with hemoglobin levels $<5 \mathrm{~g} / \mathrm{dL}$ [12]. In our center, we try to respect a threshold of $7 \mathrm{~g} / \mathrm{dL}$ of hemoglobin for blood transfusions. We accept a relative hemodilution state in the early postoperative period when most blood loss occurs, and we interrupt anti-aggregation therapy 7 days before surgery for planned operations. In addition, we pay major attention in controlling hypertension, especially in the early postoperative period. With this policy, we are able to limit blood transfusion rate after cardiac surgery to $25-30 \%$.

This study has two relative limitations. The first is that our Jehovah's Witness group is relatively small and heterogeneous $(n=31)$. On the other hand, it is an unselected group as no Jehovah's Witness was refused from surgery in our department. In addition, the diversity of the high risk surgical procedures, as stated above, differentiates our group from those evaluated in previous studies. The second limitation is the relatively long period that was considered (from 1991 to 2012). We believe that the algorithm used to select the control group (previous and next patient, of the same sex, undergoing the same procedure) neutralized most of the time effect in the group comparisons. Our results may not be upto-date with regard to absolute numbers, mainly concerning the length of stay in the hospital and intensive care unit, as there is a tendency over time for faster hospital discharges, but the between groups comparisons are probably not affected due to design of our study. Furthermore, as our hospital has no intermediate unit between the intensive care unit and the normal ward, our intensive care unit length of stay is relatively prolonged in comparison to other studies. On the other hand, our group of Jehovah's Witnesses was a nonselected group, characterized by more complex cardiac procedures, than reported in current literature, with $10 \%$ of reoperations.

\section{Conclusions}

The results of our study support the view that cardiac surgery, including complex procedures and reoperations, can be performed in Jehovah's Witnesses provided rigorous preoperative preparations, perioperative hemostasis, and postoperative management. Moreover, we confirmed that there is no difference in terms of early postoperative mortality or serious morbidity between Jehovah's Witnesses and non-Jehovah's Witness populations. It would be of interest to compare the long term mortality between Jehovah's Witnesses and non-Jehovah's Witnesses after cardiac surgery in future studies.

\section{Ethics approval and consent to participate}

This study was approved by the Brugmann University Hospital Institutional Review Board. Individual consent was waived by the committee because of the retrospective nature of the study. 


\section{Abbreviations}

CABG: coronary arterial bypass graft; FiO2: inspired fraction in oxygen; SvO2: venous saturation in oxygen.

\section{Competing interests}

All collaborators who contributed to the conception, collection of data, and writing of this manuscript were included as authors. All the authors disclose any financial or other competing interests. No source of funding is declared for any author

\section{Authors' contributions}

SM conceived of the study, and participated in its design and coordination. He participated in literature search, data collection, data analysis, data interpretation, and wrote the manuscript. PVDL carried out the data interpretation, and provided the critical revision. RT participated in data collection, data analysis and provided the critical revision. JM and CP carried out data analysis and provided the critical revision. PW conceived of the study, and participated in its design and coordination. He participated in literature search, data analysis, data interpretation, and provided the critical revision. All authors read and approved the final manuscript.

\section{Author details}

${ }^{1}$ Department of Cardiac Surgery, Brugmann University Hospital, Laeken, Belgium. ²Department of Anesthesiology, Brugmann University Hospital, Laeken, Belgium. ${ }^{3}$ Department of Intensive Care Unit, Brugmann University Hospital, Laeken, Belgium. ${ }^{4}$ Service de Chirurgie cardiaque, CHU Brugmann Université Libre de Bruxelles, 4 place A van Gehuchten, 1020 Laeken, Belgium.

Received: 14 September 2015 Accepted: 5 April 2016

Published online: 14 April 2016

\section{References}

1. Murphy GJ, Reeves BC, Rogers CA, Rizvi SI, Culliford L, Angelini GD. Increased mortality, postoperative morbidity, and cost after red blood cell transfusion in patients having cardiac surgery. Circulation. 2007;116:2544-52.

2. Koch CG, Li L, Duncan Al, Mihaljevic T, Cosgrove DM, Loop FD, et al. Morbidity and mortality risk associated with red blood cell and blood component transfusion in isolated coronary artery bypass grafting. Crit Care Med. 2006;34(6):1608-16.

3. Wells AW, Mounter PJ, Chapman CE, Stainsby D, Wallis JP. Where does blood go? Prospective observational study of red cell transfusion in north England. BMJ. 2002;325(7368):803

4. Pattakos G, Koch CG, Brizzio ME, Batizy LH, Sabik 3rd JF, Blackstone EH, et al. Outcome of patients who refuse transfusion after cardiac surgery: a natural experiment with severe blood conservation. Arch Intern Med. 2012;172(15):1154-60.

5. El Azab SR, Vrakking R, Verhage G, Rosseel PM. Safety of cardiac surgery without blood transfusion: a retrospective study in JhW patients. Anaesthesia. 2010;65(4):348-52.

6. Bhaskar B, Jack RK, Mullany D, Fraser J. Comparison of outcome in JhW patients in cardiac surgery: an Australian experience. Heart Lung Circ. 2010;19(11):655-9.

7. Stamou SC, White T, Barnett S, Boyce SW, Corso PJ, Lefrak EA. Comparisons of cardiac surgery outcomes in Jehovah's versus Non-Jehovah's Witnesses. Am J Cardiol. 2006;98(9):1223-5.

8. Chelemer SB, Prato BS, Cox Jr PM, O'Connor GT, Morton JR. Association of bacterial infection and red blood cell transfusion after coronary artery bypass surgery. Ann Thorac Surg. 2002:73(1):138-42.

9. Society of Thoracic Surgeons Blood Conservation Guideline Task Force, Ferraris VA, Ferraris SP, Saha SP, Hessel II EA, Haan CK, et al. Perioperative blood transfusion and blood conservation in cardiac surgery: the Society of Thoracic Surgeons and The Society of Cardiovascular Anesthesiologists clinical practice guideline. Ann Thorac Surg. 2007;83(5):S27-86.

10. Society of Thoracic Surgeons Blood Conservation Guideline Task Force, Ferraris VA, Brown JR, Despotis GJ, Hammon JW, Reece TB, et al. Update to the Society of Thoracic Surgeons and the Society of Cardiovascular Anesthesiologists blood conservation clinical practice guidelines. Ann Thorac Surg. 2011;91(3):944-82.
11. Bilecen S, De Groot JA, Kalkman CJ, Spanjersberg AJ, Moons KG, Nierich AP. Effectiveness of a cardiac surgery-specific transfusion protocol. Transfusion 2014;54(3):708-16

12. Carson JL, Noveck H, Berlin JA, Gould SA. Mortality and morbidity in patients with very low postoperative $\mathrm{Hb}$ levels who decline blood transfusion. Transfusion. 2002;42(7):812-8.

13. Fergusson DA, Hébert PC, Mazer CD, Fremes S, MacAdams C, Murkin JM, et al. A Comparison of Aprotinin and Lysine Analogues in High-Risk Cardiac Surgery. N Engl J Med. 2008;358:2319-31.

14. Jassar AS, Ford PA, Haber HL, Isidro A, Swain JD, Bavaria JE, et al. Cardiac Surgery in JhW Patients: Ten-Year Experience. Ann Thorac Surg. 2012;93(1):19-25.

15. Emmert MY, Salzberg SP, Theusinger OM, Felix C, Plass A, Hoerstrup SP et al. How good patient blood management leads to excellent outcomes in JhW patients undergoing cardiac surgery. Interact Cardiovasc Thorac Surg. 2011;12(2):183-8.

16. Vaislic CD, Dalibon N, Ponzio O, Ba M, Jugan E, Lagneau F, et al. Outcomes in cardiac surgery in 500 consecutive JhW patients: 21 year experience. J Cardiothorac Surg. 2012;7:95.

17. Marshall L, Krampl C, Vrtik M, Haluska B, Griffin R, Mundy J, et al. Short term outcomes after cardiac surgery in a JhW population: an institutional experience. Heart Lung Circ. 2012;21(2):101-4.

18. Moraca RJ, Wanamaker KM, Bailey SH, McGregor WE, Benckart DH, Maher TD, Magovern GJ Jr. Strategies and outcomes of cardiac surgery in Jehovah's Witnesses. J Card Surg. 2011;26(2):135-43.

19. Van der Linden $P$, Dierick $A$. Blood conservation strategies in cardiac surgery. Vox Sang. 2007;92(2):103-12.

20. Horvath KA, Acker MA, Chang H, Bagiella E, Smith PK, Iribarne A, et al. Blood transfusion and infection after cardiac surgery. Ann Thorac Surg. 2013:95(6):2194-201.

\section{Submit your next manuscript to BioMed Central and we will help you at every step:}

- We accept pre-submission inquiries

- Our selector tool helps you to find the most relevant journal

- We provide round the clock customer support

- Convenient online submission

- Thorough peer review

- Inclusion in PubMed and all major indexing services

- Maximum visibility for your research

Submit your manuscript at www.biomedcentral.com/submit 